\title{
Native Korean Speakers' Attitudes Toward Konglish as a Standardized Variety of English
}

\section{Quanisha Charles}

English Department, Composition \& TESOL, Indiana University of Pennsylvania, Indiana, USA

Email address:

q.d.charles@iup.edu

\section{To cite this article:}

Quanisha Charles. Native Korean Speakers' Attitudes toward Konglish as a Standardized Variety of English. International Journal of Literature and Arts. Vol. 3, No. 6, 2015, pp. 136-141. doi: 10.11648/j.ijla.20150306.12

\begin{abstract}
This study examines native Korean speakers' attitudes toward the use of Konglish outside of the Korean context and within an international context, as a means of conversing and negotiating with non-Koreans. The purpose of this study seeks to determine if native Korean speakers are in favor of Konglish being legitimately recognized as a standardized variety of English and the potential Konglish has of being used as a communicative tool within an international setting. Given that the English language is arguably viewed as culturally and internationally advantageous within the South Korean context, this research study aims to determine if South Koreans would feel the same way about Konglish if it were legitimately accepted as a standardized variety of English. This study also explores how native Korean speakers view their identity as English speakers, as a means of determining the effects the English language within the South Korean context.
\end{abstract}

Keywords: Konglish, English, Native-Korean Speakers (NKS)

\section{Introduction}

The ongoing debate about the varieties of English, or World Englishes, within a diverse society inspired me to examine Native-Korean Speakers' (NKS) attitudes toward Konglish (Korean + English) when spoken outside of the South Korean context. Furthermore, I was also interested in determining if South Koreans had a preferred identity when speaking English, such as to speak with an 'American' accent. Within this article, I often use the term 'native-speaker' not because I am unaware of its ideological nature, but because this term is significantly used by many of my participants within their questionnaire survey. Having taught in South Korea for three years, I was often asked by students to help them speak like an American or 'native speaker' of English (whatever that may entail). Many of the students' rationale was that they had been learning American English their entire life. As the English language teacher, I found that students were understanding and learning the English language a lot better once I incorporated Konglish words into the lesson. Students were able to connect the similarities, but many still felt that their Konglish was not "real" English and insisted that they needed to improve their English proficiency skills. Though Konglish is often used within the South Korean contexts (Byeol, 2013), some South
Koreans still view it as "broken English" or "bad English". Byeol (2013) suggested that Konglish is viewed as an informal English variety developed by South Koreans due to their failed attempts at English, but Konglish is also legitimate within the boundaries of recognizing the Korean culture.

As an English language teacher, my curiosity and interest in Konglish developed because of students' success in the classroom and a few other determinants: 1) how English is acquired through Konglish, 2) students' perception of the difference in meaning of Konglish when compared to English, and 3) ways to teach English through student familiarity of Konglish. While this current article does not necessarily target these areas, further research must be done to analyze the connection between English proficiency via the incorporation of Konglish in the language classroom. Bieswanger (2008) supports the idea of English varieties in English language teaching as a means of preparing students for cross-cultural competency, overcoming culture shock, and being prepared to face the sociolinguistic reality in unfamiliar environments.

They [English language learners] often complained about situations in which their native or non-native interlocutors had been speaking "so strangely" [i.e., employing a variety of English with which they were not familiar] that their "school English" [i.e., the English they had learned in 
secondary school] did not enable them to take part in certain English-language conversations. (Bieswanger, 2008, p. 28)

After months of research, I sought to determine if South Koreans believe that Konglish had a chance of being legitimately accepted as a standardized variety of English, considering Konglish is perceivably widely spoken and understood mainly among South Koreans. Inspired by David's (Sharifian, 2009) research, 'Non-native Chinese speakers' Views toward Intelligibility and Identity', I aimed to examine Korean English speakers' viewpoints of Konglish being used outside of the South Korean context and within an international context, among individuals who are not from South Korea. Given that the English language is viewed culturally and economically advantageous for international competitiveness by the Korean government (Byeol, 2013; Song-Ae, 2005; Song, 2011; Park, 2009), this research aimed to determine if South Koreans would feel the same way if Konglish as being culturally and economically advantageous if it were accepted as a standardized variety of English.

\section{Background}

Each year billions of dollars are spent by South Koreans and within the Korean educational system as a means of acquiring the English language (Byeol, 2013; Song, 2011). 'Korean learners, particularly at a high level of English proficiency, want to learn about English-speaking cultures, and English ways of thinking and negotiating...' (Song-Ae, 2005, p. 200). To many South Koreans, gaining English proficiency is tantamount to upward economic mobility and an increased socio-economic status (Park, 2009). Viewing English proficiency as a means to gaining upward economic mobility has certainly come at a cost. Some South Koreans have gotten tongue-surgery, put their homes up for sale to send their children abroad to predominantly English-speaking countries, such as U.S. and U.K., paid tons of money to have their children privately tutored in cram schools focused on the English language, and have gotten their newborns tongue-surgery in their infancy (Park, 2009; Byeol, 2013; Song, 2011; Park, J-K, 2009). Because of the many efforts a lot of South Koreans undertaking to acquire the English language, I aimed to explore how South Koreans identify themselves when they speak the English language. In order to address these concerns, three research questions were raised:

1. What is the NKS preferred identity when speaking English?

2. What is NKS attitude toward Konglish being legitimized as a standardized variety of English?

a) Do NKS believe that Konglish can be used at an International level as a means of negotiating with non-Koreans?

It is widely known that the English language is considered the language for international business or interlanguage of global communication. However, what may not be known is the countless number of individuals who do not speak the English language and are prevented from job opportunities, participating in worldly events, and educational opportunities, because of their lack of proficiency in the English language. In South Korea, many South Koreans face hardship and burden because of their lack of English proficiency (Park, 2009). As mentioned beforehand, some of that burden entails being denied of job opportunities, spending tons of money to acquire the English language, having tongue-surgery, and selling one's home to pay for the accumulated debt of seeking English-proficiency (Park, J-K., 2009). English is frequently equated to advancement, and proficiency in the English language is a common indication of having a privileged status within the Korean society.

Park (2009) argued that the English language dichotomizes the South Korean society by creating a privileged-class that has access to better opportunities if they are English proficient, and an under-privileged class who has grown to despise what the English language represents and its dictation of their opportunity status. In essence, South Koreans who do not speak the English language are damned if they do and damned if they don't, meaning that if they seek to learn the English language, they may be viewed as a traitor to their culture but if they do not learn the English language, they will be given fewer opportunities to succeed at the international level. Given the reality of the English language hegemony- 'the maintenance of domination...primarily through consensual social practices, social forms, and social structures...'(McLaren, 2009, p. 67) - and the opportunities opened to South Koreans who speak the English language, the debate regarding the presence of the English language in South Korea remains a consequential topic of discussion.

An example for the preference or should I say the hegemony of English language in the South Korean society can be seen in the world of sports. In 2008, the Ladies Professional Golf Association (LGPA) tour, which has been dominated by many foreign-born players, namely South Koreans, mandated that all players speak English proficiently or face losing membership (Dorman, 2008). This mandatory requirement may have likely disqualified the majority of the golf players, but more importantly, displayed the power of the English language at international events and within an international setting. What was more interesting was that instead of the golf players being against the new rule mandated by the LGPA, many embraced it and agreed that the players should learn English (Dorman, 2008). One of the players encouraged her teammates stating, "We play so good overall". When you win, you should give your speech in English' (Dorman, 2008, para. 7). This sentiment is quite problematic because it calls for South Korean players to denounce their native-language, and even culture, in the face of triumph. Canagarajah (2013) noted this act as falling victim to the hegemony of English in a postcolonial era, whereas 'non-native speakers' of English are inspired to appropriate the language rather than resist it; then they consciously or subconsciously label their own language/culture on an inferior level. Requiring English-proficiency in a sport, like golf, that does not require talkative communication at all is quite ridiculous, but this is a 
prime example of preserving the hegemony of the English language. The outcome of English requirements in sports has certainly disenfranchised individuals who are unable to afford English courses, but have tremendous golf skills. Certainly when 'native speakers' of English, who lack proficiency in other languages, play sports abroad they are not required to learn a foreign language and even more so an interpreter is provided for their convenience.

The imposition of the English language on perceivably non-English-speaking cultures has created a world where English-speaking "Western" cultures are not only admired but their needs are also consistently met. Another example is being the 'Native English Speaker' (NES) in countries, such as South Korea, where housing is provided free of charge, transportation allowance is given, and a settlement allowance offered, for NES who may or may not be certified to teach the English language. Within South Korea's public school system, a South Korean co-teacher assists the NES by ensuring their accommodation is provided and assisting with translation and other obstacles they may encounter as the 'foreign' NES. However, if individuals from perceivably non-English speaking cultures, such as South Korea, choose to teach in say, the U.S., being English-proficient is a number one requirement (Teacher Program, n.d.). While more can be problematized and certainly researched regarding the sentiments towards the English language within the South Korean context, this article will, for now, focus explicitly on NKS' attitudes toward Konglish.

\section{Methodology}

\subsection{Participants \& Design}

In order to be a part of the study, participants had to be native Korean-speakers who learned English as a second or foreign language. The rationale for this requirement is because Koreans who do not identify as native Korean speakers, meaning they speak another language as their first language, may not be aware of the hegemony of the English language in South Korea nor aware of Konglish's presence in South Korea. While this is all based on assumption, selecting native Korean-speakers who learned English as a second or foreign language assures me that they have some familiarity with the presence of Konglish within the South Korean context. The participants of this study were a total of twenty male and female South Koreans who have learned English as a foreign language. Out of the twenty participants, one of them had studied abroad in the United States and two were currently studying in the U.S. Three of the participants are purportedly applying their verbal English skills on a daily basis through either speaking with their English-speaking boyfriend or colleagues at the workplace. Thirteen out of the twenty participants mentioned that they were current English language teachers in South Korea.

Participants were contacted individually via email and asked if they were willing to complete a brief questionnaire survey regarding Konglish (See Appendix). The participants volunteered to take the survey with no funding or compensation offered or received. Surveys included a question of whether or not the participant was an English teacher and what was his or her highest level of education. Initially, I assumed that being an English teacher and education would have an impact on how the participant interpreted the data, but later on, I came to the realization that their professional or educational status is insignificant to the study as it pertains to Konglish. Interestingly, out of twenty participants, sixteen were English teachers. The data of this study were elicited using the questionnaire survey in a word document format and administered sporadically over a one-week timespan via email. There were seven questions asked in this survey and all participants were asked to answer the questions honestly. Interestingly, only one of the participants mentioned that not understanding question \#3, which asked 'who did you prefer to sound like when you speak English?' After explaining the question further to the participant, she responded, 'I want to sound like native speaker of English. Because English is their language'.

\subsection{Data Collection \& Analysis}

All data for this study was received via email after a one-week timeframe. Six surveys were received in their original word document format and fourteen surveys were received in a pdf format. In order to analyze the data, three tables were created and labeled: Korean Preferred Identity (See Table 1), NKS' Attitude towards Konglish being legitimized as a standardized variety of English (See Table 2), and Preference for Konglish use as a means of thinking and negotiating at the international level (See Table 3). I collectively grouped participant responses that were perceivably similar, according to my interpretation and categories, and I also recorded the number of participants that responded to each question.

Table 1. NKS's Preferred Identity.

\begin{tabular}{|c|c|c|}
\hline Identification & Number of Participants & Attributes \\
\hline American & 2 & Learning American English one's whole life. \\
\hline Korean & 6 & $\begin{array}{l}\text { Not easy to sound like a 'native speaker' of English or an American; } \\
\text { Accustomed to Korean pronunciation; proud Korean }\end{array}$ \\
\hline Undeclared (Native-Speaker of English) & 10 & $\begin{array}{l}\text { Speakers of the original English language; looks natural to foreigners; pride to } \\
\text { self and others; more opportunities }\end{array}$ \\
\hline N/A (Change of Preference from American) & 1 & Grammar and syntax as an English teacher are a current priority \\
\hline Multiple Identities & 1 & Easily changeable \\
\hline
\end{tabular}


Table 2. NKS Attitude Towards Konglish Being Legitimized as a Standardized Variety of English.

\begin{tabular}{lll}
\hline Yes/No/Maybe & Number of Participants & Rationale \\
\hline Yes & 7 & $\begin{array}{l}\text { All English varieties should be accepted as a tool of communication; numerous English varieties; reflects } \\
\text { culture }\end{array}$ \\
No & 9 & $\begin{array}{l}\text { Convenience for Korean people; different rules from standardized English; communication confusion; } \\
\text { constantly changing; funny } \\
\text { Just as long as it doesn't break the English rules; comprehensible to native-English speakers; numerous } \\
\text { English varieties; misunderstanding }\end{array}$ \\
Maybe & 4 &
\end{tabular}

Table 3. Konglish Use within an International Setting as a Means of Negotiating with Non-Koreans.

\begin{tabular}{lll}
\hline Yes/No/Maybe & Number of Participants & Rationale \\
\hline Yes & 6 & $\begin{array}{l}\text { Contingent upon the situation; other English varieties are used and understood } \\
\text { Informal; irrelevant to understanding culture; miscommunication with other nations; limited to South } \\
\text { No }\end{array}$ \\
Maybe & 8 & $\begin{array}{l}\text { Koreans; linguistic divide between North \& South Korea; improper use of SE } \\
\text { Convenience for people whose first language isn't English; if comprehensible to non-South Koreans; with } \\
\text { the help of gestures; to express Korean culture }\end{array}$ \\
\hline
\end{tabular}

\section{Results and Discussion}

To address the first research question, regarding $N K S$ preferred identity, research showed that a majority of South Korean participants wanted to speak English as a 'native speaker', not particularly as an individual of a certain nationality. The majority of participants mentioned that speaking English as a 'native speaker' was a sense of pride and preferred, as it indicated being a speaker of the original language. Unfortunately, none of the participants specified their meaning of 'original language' or to whom it belongs. One participant who documented preferring to speak English like a 'native speaker' mentioned 'because it's their language'. This participant's response led to the assumption is that speaking the English language as a 'native speaker' of the English language signifies that 'native speakers' of English own the English language.

There is much research arguing that because the English language is an international language, no one or single culture has the right to exclusively own the English language (Kilickaya, 2009; Canagarajah, 2013). While none of the participants recognized, at least in writing, having some sort of ownership of the English language, some participants continued to associate the 'native speaker' of English with having ownership over the English language. Moreover, many of the participants who responded with a general response (native-English speaker) did not offer a reason for their answer. Some participants who were in favor of sounding like a native-speaker of English replied 'do not to ask me why'. My assumption is that the participants did not want to be categorized at all or did not feel the need to disclose their rationale for choosing such an identity. There is also the case in which many participants believed that to sound like a 'native speaker' of English is to speak formally and be understood by everyone. Interestingly, none of the participants, with the exception of one, pointed out the variations in accents and dialects of 'native speakers' of English that may not be understood by everyone.

Those participants who gave the response that they wanted to sound like a Korean speaker who speaks English fluently explained on their survey that learning English was a part of their cultural pride and that fluency was most important, not necessarily identification. Some of the responses also entailed that because the English language being so difficult to acquire, fluency would show dedicated diligence and triumph. The two participants who preferred to speak like an American gave the response that they were accustomed to learning American English in school, so that would be their preference. The overall explanations were quite brief, which led me to believe that the participants did not put much thought into their responses or perhaps did not take the survey seriously. A participant who listed 'multiple identities' appears to have a further grasp on the phenomenon of World Englishes, due to his lengthy responses. The participant highlighted that he changed his preference for a particular identity once he began visiting other countries and hearing the varieties of English around the world. He mentioned that he was able to easily adapt and change the way he spoke English in every environment.

To address the second research question, regarding $N K S$ attitude towards Konglish being legitimized as a standardized variety of English, research showed that there was not a huge significance in the number of participants who preferred Konglish as a legitimate standardized variety of English. The majority NKS said "no" to Konglish being legitimized as a standardized variety, because they felt that Konglish was informal, comprised of Standardized English mistakes, and would confuse non-South Koreans. A few participants declined Konglish being legitimized as a standardized variety because of its variation. One participant mentioned that he was not in favor of its legitimization because it was a 'funny' type of speech. Unfortunately, this participant did not specify his notion of funny, such as viewing Konglish as comical, deceitful, or inappropriate. The seven participants who showed a positive attitude towards Konglish as a legitimate standardized variety mentioned that there are other standardized varieties around the world that are used for communication and are understood by many, even non-South Koreans. It appears that those who chose 'yes' believed that Konglish would be good for international competitiveness and a reflection of Korean culture. Seemingly, participants who chose 'maybe' were contemplating and catering to 'native speakers' of English with comments such as 'just as long as 
it's understandable to native-speakers' and 'just as long as it doesn't break the English rules'. This response leads me to believe that some South Koreans feel that Konglish could be acceptable at the international level, but only if it followed the rules according to a Standardized English (SE), thus placing English before Konglish and not on an equal-footing, and essentially preserving hegemony within the South Korean context. One participant gave the example of the Konglish term 'ice-cream' stating that it is pronounced the same in both the English and Korean language, so it is okay to use.

Regarding Konglish Use within an International Setting as a Means of Negotiating with Non-Koreans, many participants who answered 'yes' did not provide an explanation. Participants who provided an explanation mentioned that other varieties were used at the international level or that Konglish should be used under contingencies, specifically when South Koreans needed further understanding of the message being conveyed. These responses suggest that Konglish does, in fact, have potential of being used at the international level but only as a means of ensuring full comprehension to South Koreans. Many participants who answered 'no' to this question also answered no to Konglish being accepted as a legitimized standardized variety of English, highlighting that Konglish is informal, only spoken among South Koreans, and can lead to communicative misunderstandings when adopted by non-Koreans. According to many participants' responses, the need to preserve Konglish only within the South Korean context is evident. One participant stated 'no' this question, warning that the English language has already caused a dichotomy between North Korea and South Korea. Perhaps, this participant believes that using Konglish within an international setting and among non-Koreans maintains the dichotomy between mutual congruency and communication between North Korea and South Korea.

Another participant explained that Konglish should not be used at the international level because international business is formal and has nothing to do with understanding cultures. Not recognizing, using, or hearing Konglish, on a daily basis may have impacted her rationale, granted that this participant is currently studying in the U.S. My interpretation is that the participant assumes international business does not regard (inter)cultural matters and that an understanding of cross-cultural communication is not necessary; therefore, subconsciously depriving her own culture (Konglish) of being recognized within an international setting as a legitimate variety of English. Moreover, this participant, per survey, also believes that Konglish is informal and should be spoken only among South Koreans. Based on the participant's responses, it appears that a preference for integration of cultures are deemed insignificant or unwanted, and that what is seen as belonging to South Koreans should remain in South Korea. Those participants who responded as 'maybe' added conditions to their responses, 'e.g. only if gestures were involved; to explain Korean culture for people whose first language is not English'. The majority of participants who answered 'maybe' to this question sends an indication that there is a possibility for Konglish to be used and articulated for international business, but with further support and under certain circumstances. Overall, the number of participants who answered 'yes' and 'no' were equally the same.

Only after collection of data, I realized that some of the survey questions may not have been clear to the participants. Two of the participants, who noted studying in the U.S., recommended that I define the term Konglish beforehand, because of its obscure meaning. Lacking clarity of interview questions were consequential to the survey results. Due to the obscurity of Konglish's meaning, on the one hand, some participants may have judged Konglish based on the idea of it as a misuse of the English language, where Korean and English words are mixed, e.g. nun shopping, which translates to eye-shopping but it is more commonly known in the Western society, such as the U.S., as window-shopping (Byeol, 2013).

On the other hand, some participants may have answered the survey questions based on a meaning of Konglish whereas English '[...] words that have been phonetically modified in order to fit the pronunciative governing structure of the Korean language' (Byeol, 2013, p. 265). Using Korean-pronunciative English, e.g. washee vs. wash, may also explain the high number of South Koreans who chose to be identified as a Korean who speaks English fluently rather than someone of a different nationality. Data from the questionnaire surveys pinpoint a decent percentage of South Koreans who may have chosen their answers based upon Konglish being recognized as Korean-pronounciative English. Moreover, the complexity and ambiguity of the definition of Konglish shows that there are instances where Konglish can also refer to English words used to convey a visionary structure, meaning some South Koreans misidentify Korean-coined Konglish terms for English terms (Song, 2011). While the various meanings of Konglish further complicates its use and international understanding, e.g. the Konglish word 'service' is understood by South Koreans as a complimentary gift but by others, the word 'service' may be known as some sort of laborious undertaking, this does not warrants the possibility of its recognition as a legitimized standardized variety of English.

\section{Conclusion}

Due to the scarcity of research focused specifically on the legitimization of Konglish as a standardized variety of English being used within an international setting among non-Koreans, further empirical research is needed. Certainly, many of the participants provided their opinions that may have been very well biased because Konglish within an international setting to communicate with non-Koreans has yet to be instantiated. Acknowledging and realizing one's own cultural linguistics within an international setting spoken by many non-Koreans may likely change many opinions of the participants who were initially not in favor of Konglish being used internationally or legitimized as a standardized variety of English.

After collecting and reviewing the questionnaire surveys, I also noticed that many South Koreans do believe that Konglish is something that they own and would like to keep within their own culture and outside of international relations. The reason 
for this may be that some South Koreans fear if Konglish is promoted at the international level and disseminated to other nations to learn and acquire, it will no longer be considered Konglish or something belonging exclusively to their culture and may eventually evolve into something a variety of its variety. One participant pointed out that she only understands Konglish when it is used by fellow South Koreans explaining, ' $I$ already mention Konglish only has to be used between people who speak Korean.' This participant was also in favor of a Standardized English being maintained at the international level. It appears that some people, in this case South Koreans, are not inclined to see past the English language as merely a lingua franca that is also comprised of variations (Bieswanger, 2008; Canagarajah, 2013). Moreover, some individuals may feel that the English language must maintain its standardization, lest it becomes incomprehensible. However, the English language has already been adapted, hence Scottish English, Old English, American English, etc. Of course, any language used within an international setting will be treated as a commodity and certainly operating Konglish at the international level is no exception.

Without a doubt, there are many 'non-native speakers' of English who prefer the use of Standardized English within an international setting and strive to speak the English language like a 'native speaker' (whatever that may entail), and they have every right to do so. However, the use of incorporating one's variety of English, in this case Konglish, to develop English language proficiency is heavily encouraged. While research shows that a large number of South Koreans are not in favor of Konglish being legitimized as a standardized variety of English, a decent number are in favor of Konglish being used within an international setting to communicate with non-Koreans. It appears that Konglish has the potential of being a middling for both Koreans and non-Koreans to communicate. It especially is a middling and huge asset for English language teachers planning to teach the English language in South Korea, as it shows that the individual is acknowledging South Korean culture and working toward establishing a culturally-responsive, 'a pedagogy that recognizes the importance of including students' cultural references in all aspects of learning' (Fredericks, p. 158) environment.

\section{Appendix}

Directions: Please complete the five short questions below as honest as possible. Feel free to expand your answers.

1. Are you an English Teacher? Yes or No.

2. Please indicate the highest level of education you completed.

3. Who do you prefer to sound like when you speak English? (E.g. A native-speaker of English. An American. A Korean who speaks English fluently.) Please explain why.

4. How do you feel about Konglish spoken outside of the Korean context? Please explain why.

5. Should Konglish be accepted as a legitimate variety of English? Why or Why not?
6. If Konglish were accepted on the international level as a standardized variety of English, should it adopt the phonetics and pronunciative spelling of the English language so that it is better understood by everyone? (E.g. sileob vs. syrup) Why or Why not?

7. Do you believe it is possible to use Konglish as a means of thinking and negotiating at the international level? Why or Why not?

\section{References}

[1] Bieswanger, M. (2008). Varieties of English in current English language teaching. Stellenbosch Papers in Linguistics, 38(1), 27-47.

[2] Byeol, K. S. (2013). Excuse my Konglish. Retrieved 9/20/2015 from

http://www.iafor.org/offprints/acll2013-offprints/ACLL2013_ Offprint_0138.pdf

[3] Canagarajah, S. (2013). Translingual practice: Global Englishes and cosmopolitan relations. New York, NY: Routledge.

[4] Dorman, L. (2008). Golf Tour's Rule: Speak English to Stay in Play. The New York Times. Retrieved 9/25/2015 from http://www.nytimes.com/2008/08/27/sports/golf/27golf.html? pagewanted $=$ all\&_r $=0$

[5] Fredericks, J.A. (2014). Eight myths of student disengagement: Creating classroom of deep learning. London, U.K.: Sage

[6] Kilickaya, F. (2009). World Englishes, English as an international language and applied linguistics. English Language Teaching, 2(3), 35-38.

[7] McLaren, P. (2009). Critical pedagogy: A look at major concepts. In A. Darder, M.P. Baltodano, \& R. Torres (Eds), The critical pedagogy reader ( $2^{\text {nd }}$ edition). New York: NY: Routledge.

[8] Park, J. (2009). The local construction of a global language. Ideologies of English in South Korea. Berlin, Boston: De Gruyter Mouton.

[9] Park, J-K. (2009). 'English fever' in South Korea: Its history and symptoms. 'Education fever' drives the demand for English in South Korea today. English Today 97, 25(1), 50-57.

[10] Sharifian, F. (ed.) (2009). English as an International Language: Perspectives and Pedagogical Issues. Clevedon, UK: Multilingual Matters.

[11] Song-Ae, H. (2005). Good teachers know where to scratch when learners feel itchy: Korean learners' views of native-speaking teachers of English. Australian Journal of Education (ACER Press), 49(2), 197-213.

[12] Song, J. J. (2011). English as an official language in South Korea: Global English or social malady? Language Problems \& Language Planning, 35(1), 35-55. doi:10.1075/lplp.35.1.03son

[13] Teacher program. (n.d.). In J-1 visa exchange visitor program. Retrieved 9/20/2015 http://j1visa.state.gov/programs/teacher 